Article

\title{
A Comparative Study between Bimetallic Iron@copper Nanoparticles with Iron and Copper Nanoparticles Synthesized Using a Bioflocculant: Their Applications and Biosafety
}

\author{
Nkosinathi Goodman Dlamini ${ }^{1, * \mathbb{D}}$, Albertus Kotze Basson ${ }^{1}$ and \\ Viswanadha Srirama Rajasekhar Pullabhotla $2, *$ (D) \\ 1 Department of Biochemistry and Microbiology, University of Zululand, Private Bag X1001, \\ KwaDlangezwa 3886, South Africa; BassonA@unizulu.ac.za \\ 2 Department of Chemistry, University of Zululand, Private Bag X1001, KwaDlangezwa 3886, South Africa \\ * Correspondence: nathidlamini03@gmail.com (N.G.D.); PullabhotlaV@unizulu.ac.za (V.S.R.P.); \\ Tel.: +27-35-902-6155 (V.S.R.P.)
}

Received: 20 July 2020; Accepted: 19 August 2020; Published: 10 September 2020

\begin{abstract}
Nanotechnology addresses numerous environmental problems such as wastewater treatment. Ground water, surface water and wastewater that is contaminated by toxic organic, inorganic solutes and pathogenic microorganisms can now be treated through the application of nanotechnology. The study reports iron@copper (Fe@Cu) nanoparticles, iron nanoparticles (FeNPs) and copper nanoparticles (CuNPs) synthesized using a bioflocculant in a green approach technique. Characterization of the as-synthesized materials was achieved using analytical techniques such as Fourier transform-Infrared spectroscopy (FT-IR), Thermogravimetric analysis (TGA), Scanning Electron Microscope (SEM), Transmission Electron Microscopy (TEM), UV-Vis spectroscopy (UV-Vis) and X-ray diffraction (XRD). The presence of hydroxyl $(-\mathrm{OH})$ and amine $\left(-\mathrm{NH}_{2}\right)$ groups was shown by FT-IR spectroscopy studies and the as-synthesized material was shown to be thermostable. Elements such as oxygen, carbon, iron and copper were found to be abundant in $\mathrm{Wt} \%$. Absorption peaks were found between 200 and $390 \mathrm{~nm}$ wavelength and diffraction peaks at $2 \theta-29^{\circ}, 33^{\circ}$ and $35^{\circ}$ for FeNPs, CuNPs and Fe@Cu, respectively. In their application, the effect of various parameters on the flocculation activity were evaluated. Both the CuNPs and (Fe@Cu) nanoparticles have shown the best flocculation activity at a concentration of $0.2 \mathrm{mg} / \mathrm{mL}$ with over $90 \%$ activity, while the dosage size with a concentration of $0.4 \mathrm{mg} / \mathrm{mL}$ was optimal for FeNPs. The FeNPs were found to be cation dependent, while CuNPs and Fe@Cu nanoparticles flocculate in the absence of a cation and flocculate both in acidic and alkaline $\mathrm{pH}$. All the synthesized nanoparticles are thermostable and maintain flocculation activity above $80 \%$ at $100{ }^{\circ} \mathrm{C}$. Both the Fe@Cu and CuNPs were found to be effective in removing dyes with the removal efficiency above $89 \%$ and were found to be effective in removal of chemical oxygen demand (COD) and biochemical oxygen demand (BOD) in Mzingazi river water and coal mine wastewater with over $80 \%$ removal efficiency. Moreover, the synthesized nanoparticles showed some remarkable antimicrobial properties when evaluated against Gram-positive and Gram-negative bacteria. The as-synthesized material was found to be safe to use at low concentration when verified against human embryonic cells (HEK293) and breast cancer cells (MCF7) and biodegradable.
\end{abstract}

Keywords: bioflocculant; flocculation activity; wastewater treatment; dye removal; iron nanoparticle; copper nanoparticles 


\section{Introduction}

Water contamination by a series of pollutants, especially heavy metals, dyes and pigments from textile industries, and other suspended toxic particles, remains a threat to environment and public health. Consequently, measures should be taken to control the discharge of these toxic products to the environment and water bodies [1]. Numerous methods have been employed to remove contaminants from wastewater both physically and chemically which include, ion-exchange, flocculation, reverse osmosis, electrodialysis and neutralization [2,3].

Flocculation is the most popular of the above-mentioned techniques due to its economic viability and effectiveness. The flocculation technique uses flocculants namely: organic synthetic flocculants, inorganic flocculants and naturally occurring bioflocculants [4]. Numerous textile industries use dyes in their product processing; as a result, water contaminated with dyes is released as a by-product [5]. Environmental and health concerns have been raised over the use of organic and inorganic flocculants, while bioflocculants are environmentally friendly, biodegradable and possess no health hazards [4]. Inorganic particles, with nano size of either simple or composite, possess exceptional physico-chemical properties which render them effective for various nanotechnological applications such as biomedical, biological, pharmaceutical and wastewater treatment $[6,7]$. The opportunity to develop water supply systems for the future generation is provided by nanotechnology. The current water system is not reliable as it relies on conveyance i.e., water is pumped through pipes that get rusty and burst frequently. Nanotechnology is envisaged to provide high performance, highly efficient, flexible and multifunctional processes which will result in affordable water treatment solutions [8]. With the emergence of antibiotic resistant microorganisms to multiple antibiotics, contamination of water poses a major threat to public health [9]. Flocculants based on iron and/or copper as precursors are gaining interest in wastewater treatment, this could be due to the interesting properties these elements possess, such as antimicrobial activity, the ability to remove dyes and flocculation, and could remove pollutants in different wastewater samples [10-14].

Several reports have been documented on nanoparticle synthesis; these methods include those that are physical, chemical and biological [15-19]. However, bimetallic synthesis using microbial molecules such as a polysaccharide bioflocculant is scarce in literature. Furthermore, the comparative study of single metallic and bimetallic nanoparticle application is very rare in the available literature, hence, the significance of the current study. Here, we provide the use of bioflocculant passivated nanoparticles from Alcaligenes faecalis HCB2 (see our previous work) [20] of marine origin for the treatment of wastewater, river water and dye removal. Furthermore, the study provides the cytotoxicity test of nanoparticles on HEK293 human embryonic cells and MCF7 breast cancer cells. Lastly, the study seeks to ascertain the biodegradation of nanoparticles by microorganisms from soil samples collected from dried sludge from domestic wastewater.

\section{Materials and Methods}

\subsection{Synthesis of FeNPs, CuNPs and Fe@Cu Nanoparticles}

Metal precursors iron sulphate and copper sulphate were dissolved in distilled water, separately, to make a concentration of $3.0 \mathrm{mM}$, respectively. Subsequently, $0.5 \mathrm{~g}$ of previously extracted and purified bioflocculant was added in both solutions and mixtures were shaken at room temperature in a shacking incubator for 5-10 $\mathrm{min}$ and was left standing for $24 \mathrm{~h}$ at room temperature. The formed precipitate was collected by centrifugation at $4{ }^{\circ} \mathrm{C}, 8000 \mathrm{rpm}$ for $15 \mathrm{~min}$. Through physical observation and characterization, the synthesis of both copper and iron nanoparticles was confirmed. The control was maintained without addition of bioflocculant with the experimental flask containing iron sulphate and copper sulphate solutions (see our previous work) [21,22].

A modified method as described by $\mathrm{Yu}$, et al. [23] was adopted for the synthesis of Fe@Cu nanoparticles, where $10 \mathrm{~mL}$ of $0.03 \mathrm{M} \mathrm{FeSO}_{4}$ aqueous solution was prepared in a volumetric flask, after the solution was transferred into a conical flask and $0.5 \mathrm{~g}$ of bioflocculant was added (reducing agent). 
A $10 \mathrm{~mL}$ of $5.0 \mathrm{M} \mathrm{NaOH}$ as a stabilizing agent was added to the solution of $\mathrm{FeSO}_{4}$ at room temperature. The formed precipitate was collected after $24 \mathrm{~h}$ at a temperature of $4{ }^{\circ} \mathrm{C}, 8000 \mathrm{rpm}$ as indicated above and washed with absolute ethanol to remove impurities. Furthermore, different volumes of formed FeNPs, 10,20 and $30 \mathrm{~mL}(1 \mathrm{mg} / \mathrm{mL})$ were mixed successively with a solution of $\mathrm{CuSO}_{4}(0.003 \mathrm{M})$ in $6.0 \mathrm{~mL}$ of $5.0 \mathrm{M}$ glucose that served as stabilizing agent [24]. This reaction was allowed to continue for $20 \mathrm{~min}$ and the resulting precipitates were collected by centrifugation at 15,000 rpm for $30 \mathrm{~min}$ at a temperature of $4{ }^{\circ} \mathrm{C}$. Nomoev, et al. [25] alluded that among other physical mechanisms involved in bimetallic and core-shell nanoparticles formation is surface tension differences, differences in melting temperature of the component materials and relative vapor concentration of the materials. However, for this particular study, we propose physisorption as the mechanism responsible for the formation of nanoparticles since there is no electron beam involved, but further characterization of the synthesized material is necessary to ascertain this.

\subsection{Characterization of FeNPs, CuNPs and Fe@Cu Nanoparticles}

The optical measurements on the synthesized FeNPs, CuNPs and Fe@Cu nanoparticles were carried out using Varian Cary 50 Conc UV-Vis spectrophotometer (PerkinElmer, Gauteng, South Africa). The UV-Vis analysis was carried out at room temperature conditions using dilute samples of the FeNPs, CuNPs and Fe@Cu nanoparticles at a wavelength region 300-700 nm and $1 \mathrm{~nm}$ resolution. The Tensor 27, Bruker FT-IR (Bruker, Gauteng, South Africa) spectrophotometer was used to run the Fourier Transform-Infrared (FT-IR) analysis on the bioflocculant and synthesized FeNPs, CuNPs and Fe@Cu nanoparticles. The parameters used were in the range $4000-200 \mathrm{~cm}^{-1}$ at $4 \mathrm{~cm}^{-1}$ resolution. The detection of the functional groups present in the pure dry samples of FeNPs, CuNPs and Fe@Cu nanoparticles were identified using the finely ground dry powders of the samples.

The morphology of the synthesized FeNPs, CuNPs and Fe@Cu nanoparticles were measured using a JEOL JSM-6100 microscope equipped with an energy-dispersive X-ray analyzer (EDX) (JEOL USA, Inc., Peabody, Massachusetts 01960, USA). The fine dry samples of synthesized FeNPs, CuNPs and Fe@Cu nanoparticles were placed on copper stubs using double-sided carbon tape. These samples were carbon coated using a JEOL vacuum evaporator. The scanning electron microscopy (SEM) images were taken using the following conditions: Tungston (W) filament, emission current-100 $\mu \mathrm{A}$, accelerating voltage $-10 \mathrm{kV}$, working distance of 5-10 nm. EDX measurements were taken using JEOL JSM 6100 SEM with Bruker Quantax Esprit software. TEM images were taken using the JEOL 1010 transmission electron microscope (JEOL USA, Inc., Peabody, Massachusetts 01960, USA) by placing a drop of the sample of synthesized FeNPs, CuNPs and Fe@Cu nanoparticles on a copper grid (150 mesh size) (Agilent Technologies, Gauteng, South Africa). The TEM images were obtained using the Megaview III camera and were viewed at $100 \mathrm{kV}$ accelerating voltage.

The diffraction patterns of synthesized FeNPs, CuNPs and Fe@Cu nanoparticles were obtained using the Bruker D8 Advance diffractometer (Bruker, Gauteng, South Africa) equipped with Cu-K $\alpha$ radiation $(\lambda=1.5406 \AA)$. The diffraction patterns were recorded at room temperature by placing the dry powder of the sample on the sample holder, with operating conditions of $40 \mathrm{kV}$ and $40 \mathrm{~mA}$. Perkin-Elmer Thermal Analysis Pyris 6 TGA (PerkinElmer, Inc., Waltham, MA 02451, USA) was used for the thermogravimetric analysis of synthesized FeNPs, CuNPs and Fe@Cu nanoparticles. The degradation patterns of the samples were obtained with the nitrogen gas flow rate at $40 \mathrm{cc} / \mathrm{min}$ and the temperature range 22 to $900{ }^{\circ} \mathrm{C}$ with ramping of the temperature at $10{ }^{\circ} \mathrm{C} / \mathrm{min}$.

\subsection{Flocculation Activity of CuNPs, FeNPs and Fe@Cu Nanoparticles}

Dosage size is defined as the amount of required flocculant powder for optimal flocculation activity. Different nanoparticle concentrations were prepared by dissolving different milligrams $(0.2-0.8 \mathrm{mg} / \mathrm{mL})$ of nanoparticles (FeNPs, CuNPs and Fe@Cu) in distilled water. Each ditto was dissolved in $50 \mathrm{~mL}$ distilled water. Subsequently, $4.0 \mathrm{~g} / \mathrm{L}$ of kaolin clay solution was prepared in distilled water. The mixture of $2.0 \mathrm{~mL}$ of nanoparticles (FeNPs, CuNPs and Fe@Cu) solutions and $3.0 \mathrm{~mL}$ of $1 \%(w / v) \mathrm{CaCl}_{2}$ and 
$100 \mathrm{~mL}$ kaolin clay was added and agitated for $1 \mathrm{~min}$ in a $250 \mathrm{~mL}$ conical flask. After which, the mixture was transferred to a $100 \mathrm{~mL}$ graduated measuring cylinder and left to stand for $5 \mathrm{~min}$. The supernatant was analyzed in a UV-Vis spectrophotometer Pharo 300 Spectroquant ${ }^{\circledR}$ at $550 \mathrm{~nm}$ [26]. The test was realized according to $\mathrm{Xia}$, Lan, $\mathrm{Li}, \mathrm{Xie}$, Liang, Yan, Chen and Xing [26]. The following equation was used to calculate flocculation activity:

$$
F A(\%)=\frac{A-B}{A} \times 100
$$

where $A=$ optical density of control at $550 \mathrm{~nm}$ and $B=$ optical density of sample at $550 \mathrm{~nm}$.

\subsection{Application of Nanoparticles in Wastewater Treatment}

Wastewater samples used during experiment modelling were collected from three different sampling sites viz. the Tendele coal mine, Vulindlela treatment plant and Mzingazi river. All the sampling sites sites are in KwaZulu Natal province of South Africa. Domestic wastewater, river water and coal mine wastewater was collected to evaluate the effectiveness of nanoparticles (CuNPs, FeNPs and Fe@Cu) on the removal of pollutants. The optimum dosage for each nanoparticle as indicated above was used for the subsequent test. Removal of different pollutants, such as COD, BOD, phosphate and total nitrogen was evaluated using test kits, following the manufactures protocol [7]. UV-Vis Pharo 300 Spectroquant ${ }^{\circledR}$ was used to analyze removal efficacy of COD, BOD, total nitrogen and phosphate contents by nanoparticles at $680 \mathrm{~nm}$. The removal efficiency (RE) of the pollutants was calculated by the following equation:

$$
R E(\%)=\left(C_{0}-C_{1}\right) / C_{0} \times 100
$$

where $C_{0}$ is the initial value and $C_{1}$ is the value after the flocculation treatment. The flocculating efficiency of the synthesized nanoparticles and the conventionally used chemical flocculants was compared. The chemical flocculant used was ferric chloride [27].

\subsection{Application of Nanoparticles in Dyes Removal}

A method as described by Dlamini et al. [7] was adopted to evaluate dye removal efficiency by nanoparticles. A solution of $4 \mathrm{~g}$ in $1000 \mathrm{~mL}$ distilled water was prepared for all experimental dyes (safranin, methylene blue, methylene orange, malachite green). Optimal dosage for each nanoparticle solution was added in $100 \mathrm{~mL}$ dye solution i.e., $2 \mathrm{~mL}$ of nanoparticles in $100 \mathrm{~mL}$ dye solution. The mixtures were allowed 10 min contact time before supernatant was taken for analysis at maximum wavelength of $610 \mathrm{~nm}$ for each dye using UV-Vis spectrophotometer Pharo 300 Spectroquant ${ }^{\circledR}$. Decolourization efficiency was calculated using the (RE) equation as indicated above.

\subsection{Cytotoxicity of Nanoparticles}

A method described by Daniels and Singh [28] was used to ascertain cytotoxicity of the nanoparticles using a human embryonic kidney (HEK 293) and breast cancer cells (MCF-7). The 96-well-plates were used for plating the cells with cell suspensions of $1 \times 10^{5}$ cells $/ \mathrm{mL}$ concentrations. After $48 \mathrm{hrs}$ incubation, the cells were seeded with different concentrations of nanoparticles $(25-100 \mu \mathrm{g} / \mu \mathrm{L})$ using a tenfold serial dilution method, media containing $1 \%$ of fetal bovine serum (FBS) were used for the administration of nanoparticles and the plates were returned to the incubator for $48 \mathrm{~h}$. Tetrazolium salt (Sigma) was added as an indicator after $48 \mathrm{~h}$ of incubation to ascertain cell viability. $15 \mu \mathrm{L}$ of 3-(4,5-dimethylthiazol-2-yl)-2,5-diphenyl tetrazolium bromide (MTT) $\left(5 \mathrm{mg} / \mathrm{mL}\right.$ ) in phosphate buffered saline (PBS) was added to each well and incubated at $37^{\circ} \mathrm{C}$ for $4 \mathrm{~h}$. After sucking off from the wells the medium with MTT and the formed formazan crystals were dissolved in $100 \mu \mathrm{L}$ of dimethyl sulfoxide (DMSO). The optical density of the solutions was measured at $570 \mathrm{~nm}$ using a micro plate reader. The $\%$ cell inhibition was determined using following formula: 
Cell viability $(\%)=\left(\mathrm{F}_{1} / \mathrm{F}_{0}\right) \times 100$; where $\mathrm{F}_{1}$ and $\mathrm{F}_{0}$ are the final values obtained after and before treatment with the nanoparticles, respectively.

\subsection{Antimicrobial Effect of Nanoparticles}

\subsubsection{Bacterial Strains Resuscitation}

All media used were obtained from Sigma-Aldrich (St Louis, MO, USA). To determine the antimicrobial activity of nanoparticles (CuNPs, FeNPs and Fe@Cu) were tested against Gram-positive and Gram-negative microorganisms. Bacillus subtilis CSM5 and Escherichia coli ATCC $25922(1.0 \mathrm{~mL})$ were inoculated into different $9.0 \mathrm{~mL}$ sterile nutrient broths contained in the test tubes. The inoculum was incubated at $37^{\circ} \mathrm{C}$ for $24 \mathrm{~h}$. A spectrophotometer $(600 \mathrm{~nm})$ was used to determine the bacterial turbidity/absorbance. The turbidity was adjusted to be in line with the McFarlan standards (0.5).

\subsubsection{Minimum Inhibitory Concentration (MIC) and Minimum Bactericidal Concentration (MBC)}

The antimicrobial activity study was achieved through the 96-microplate-well method with $40 \%$ ciprofloxacin as a positive control in this experiment. A series of $(50 \mu \mathrm{L})$ dilutions were prepared using 96-micro-well plates. Sterile nutrient broth $(50 \mu \mathrm{L})$ was poured in all wells followed by the addition of $50 \mu \mathrm{L}$ of bacterial strain into the corresponding wells from the highest concentration until the lowest concentration. To achieve the required concentration $50 \mu \mathrm{L}$ nanoparticles (CuNPs, FeNPs and Fe@Cu) was added into to the first row of the 96-microplate's wells which was followed by a series of dilutions from the highest concentration to the lowest. Distilled water was used as a negative control for this experiment while $p$-iodonitrotetrazolium (INT) was used as an indicator [29].

The synthesized nanoparticles' minimal inhibitory concentration (MIC) was determined as described by Eloff [30]. The MBC was evaluated for the plates, which indicated a positive MIC. Loops full of culture from each strain from the well, which indicated no color change, were streaked on a Mueller Hilton nutrient agar. The plates were incubated at $37^{\circ} \mathrm{C}$ for $12 \mathrm{~h}$. The lowest concentration of nanoparticles that exhibited the complete killing of the test organisms were considered as the MBC.

\subsection{Biodegradability of the Synthesized Nanoparticles}

To ascertain biodegradability of the synthesized nanoparticles (CuNPs, FeNPs and Fe@Cu) a method described by Mittal, et al. [31] was adopted with some minor modifications. Soil samples were collected from Vulindlela wastewater treatment plant using sterile Petri dishes. Domestic wastewater is regularly discharged in the plant, which makes the wastewater treatment plant a great environment for the growth of diverse microorganisms, which are capable of degrading a variety of contaminants (the plant is located close to the University of Zululand, RSA) after which, $4.0 \mathrm{~g}$ of soil sample was mixed with $0.2 \mathrm{~g}$ of nanoparticles. To ensure that microbes in the soil sample are kept alive, the effluent from the treatment plant was consistently sprinkled in the soil sample. A soil sample of $4.0 \mathrm{~g}$ and $0.2 \mathrm{~g}$ of the nanoparticles was left uncovered to mimic the environment from which the microbes were sampled. At the end of every week the soil sample was firstly dried using a microwave oven at $37^{\circ} \mathrm{C}$ before it was weighed [32]. This was performed in order to monitor the biodegradation process and was done for 7 weeks. The following formula was used to calculate the remaining weight of the flocculant after degradation:

$$
\mathrm{r}=\mathrm{Wm}-\mathrm{Ws}
$$

where $\mathrm{Wr}$ is the remaining weight after degradation, Wm weight of the mixture of soil sample and nanoparticles and Ws is the weight of the soil. All the experiments were conducted in triplicate and the mean values were collected. 


\subsection{Experimental, Software and Statistical Analysis}

All data were collected in triplicate and the error bars in the Figures show the standard deviations of the data. Data were subjected to one-way analysis of variances (ANOVA) using GraphPad Prism ${ }^{\mathrm{TM}}$ ver. 6.1. A significant level of $p<0.05$ was used.

\section{Results}

\subsection{Characterization of Nanoparticles}

Characterization of the as-synthesized nanomaterials was performed using UV-vis spectroscopy, Fourier transform-infrared spectroscopy (FT-IR), Thermogravimetric analysis (TGA), Scanning Electron Microscope (SEM), Transmission Electron Microscopy (TEM) and X-ray diffraction (XRD). The characterization data for the synthesized material is provided in the form of supplementary data.

\subsection{Effect of Nanoparticles Concentration on Flocculation Activity}

Figure 1 showed the results of nanoparticles (FeNPs, CuNPs and Fe@Cu) dosage concentration effect on the flocculation activity. Fe@Cu nanoparticles had the highest flocculation activity compared to both FeNPs and CuNPs.

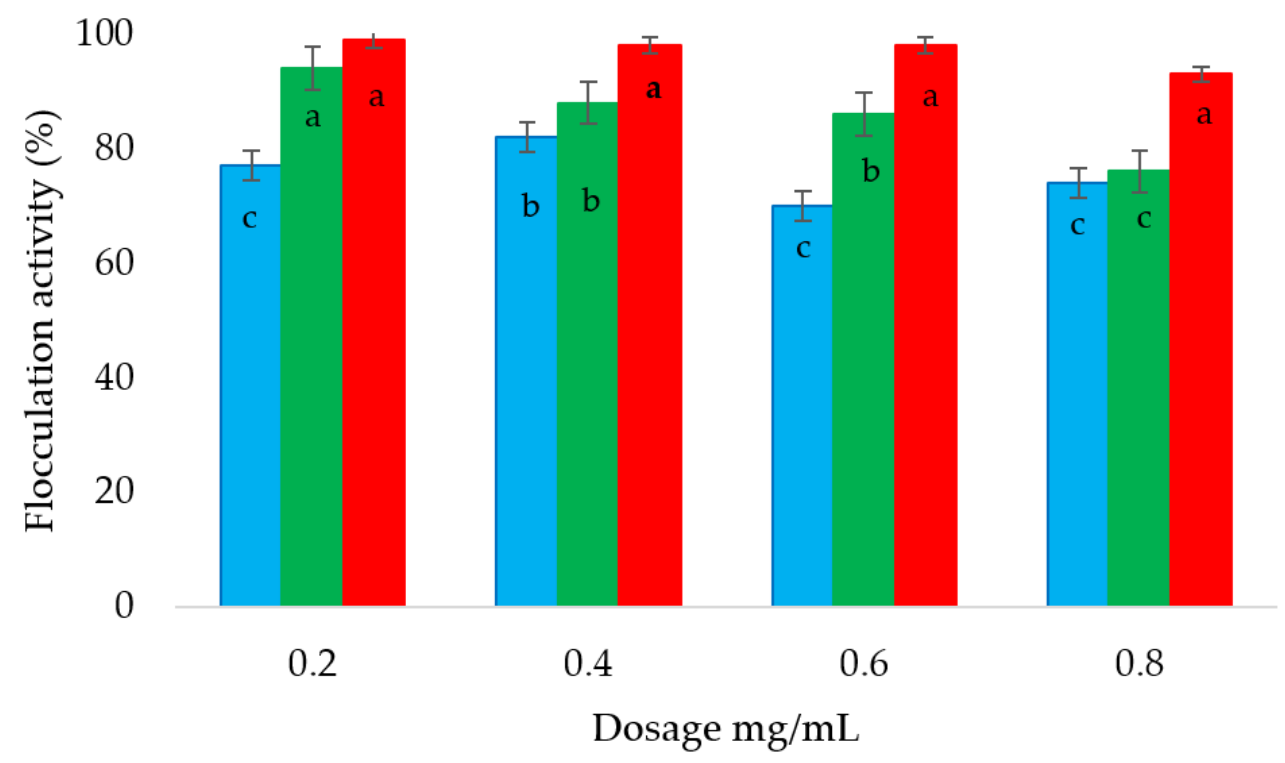

\section{FeNPs $\square$ CuNPs $\square \mathrm{Fe} @ \mathrm{Cu}$}

Figure 1. Effect of nanoparticles dosage concentration on the flocculation activity at room temperature different letters $(\mathrm{a}, \mathrm{b}$ and $\mathrm{c})$ denotes statistical significance at $(p<0.05)$.

\subsection{Effect of Cations on Flocculation Activity}

Table 1, below, represents the results obtained during the determination of the effect of cations on flocculation activity of nanoparticles (FeNPs, CuNPs and Fe@Cu). Both CuNPs and Fe@Cu nanoparticles are cation independent as the flocculation activity was above $95 \%$ without the addition of cations. Meanwhile, the FeNPs were highly dependent on a cation because the flocculation activity was below $50 \%$ in the absence of cation.

\subsection{The Effect of $p H$ on Flocculation Activity of Nanoparticles}

Figure 2 shows the effect of $\mathrm{pH}$ on flocculation activity of nanoparticles. Fe@Cu nanoparticles work best in all $\mathrm{pH}$ ranges, while CuNPs was observed to flocculate less at acidic $\mathrm{pH}$ with the maxim flocculation observed at neutral $\mathrm{pH}$. On the other hand, FeNPs flocculate best at alkaline $\mathrm{pH}$. 
Table 1. Effect of cations presence on the flocculation activity at room temperature.

\begin{tabular}{ccccc}
\hline \multirow{2}{*}{ Flocculant Type } & \multicolumn{4}{c}{ Cations FA(\%) $\pm \mathbf{S D}{ }^{*}$} \\
\cline { 2 - 5 } & Control & $\mathbf{N a}^{+}$ & $\mathbf{C a}^{\mathbf{2 +}}$ & $\mathbf{F e}^{\mathbf{3 +}}$ \\
\hline CuNPs & $96 \pm 0.0^{\mathrm{a}}$ & $86 \pm 0.1^{\mathrm{b}}$ & $94 \pm 0.0^{\mathrm{a}, \mathrm{b}}$ & $97 \pm 0.2^{\mathrm{a}}$ \\
FeNPs & $42 \pm 0.1^{\mathrm{d}}$ & $73 \pm 0.0^{\mathrm{c}}$ & $82 \pm 0.1^{\mathrm{b}, \mathrm{c}}$ & $85 \pm 0.3^{\mathrm{b}}$ \\
Fe@Cu & $95 \pm 0.3^{\mathrm{a}}$ & $97 \pm 0.2^{\mathrm{a}}$ & $99 \pm 0.2^{\mathrm{a}}$ & $97 \pm 0.0^{\mathrm{a}}$ \\
\hline
\end{tabular}

* Values represent mean \pm deviation of replicate readings. Percentage flocculating activities with different letters $(a, b, c$ and $d)$ are significantly $(p<0.05)$ different.

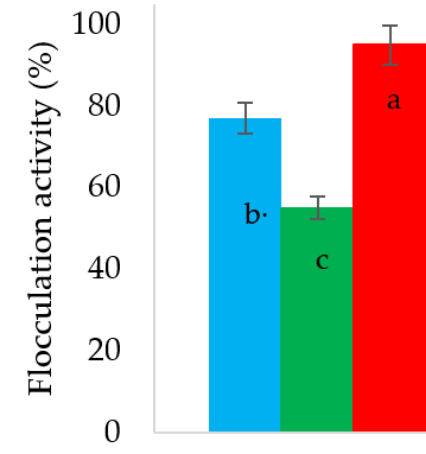

3

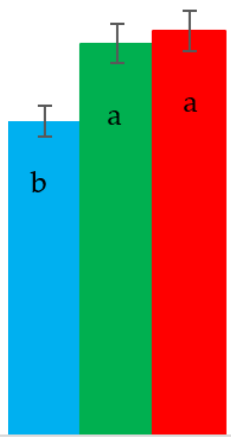

7

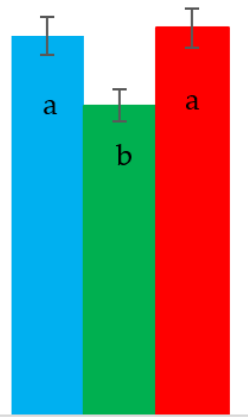

11

$\mathrm{pH}$

\section{FeNPs $\square \mathrm{CuNPs} \square \mathrm{Fe} @ \mathrm{Cu}$}

Figure 2. Effect of $\mathrm{pH}$ on flocculation activity of nanoparticles at room temperature different letters $(\mathrm{a}, \mathrm{b}$ and $\mathrm{c})$ denotes statistical significance at $(p<0.05)$.

\subsection{Effect of Temperature on Flocculation Activity of Nanoparticles}

Figure 3 shows the effect of temperature on flocculation activity of nanoparticles (FeNPs, CuNPs and Fe@Cu). All synthesized nanoparticles were found to be thermally stable with a flocculation activity above $88 \%$ at $100{ }^{\circ} \mathrm{C}$.

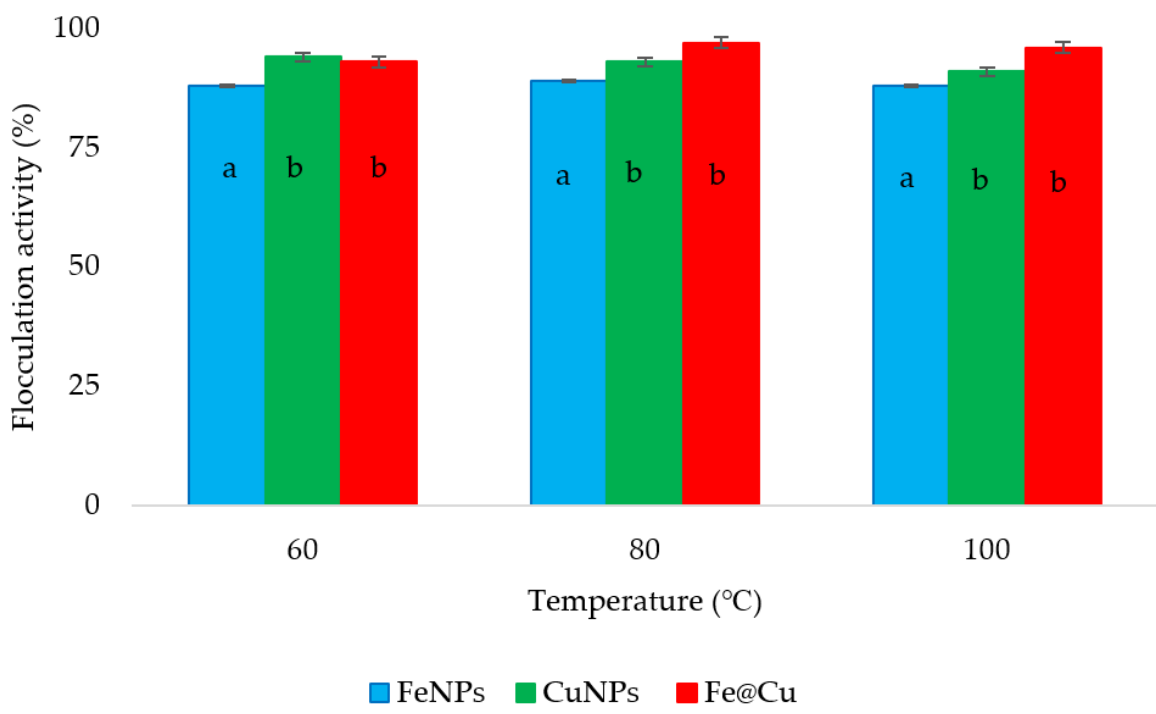

Figure 3. Effect of temperature on the flocculation activity at room temperature different letters ( $a$ and $b$ ) denotes statistical significance at $(p<0.05)$. 


\subsection{Application of Nanoparticles in Dye Removal}

Figure 4 illustrates the of nanoparticles (FeNPs, CuNPs and Fe@Cu) application in dye removal. Both the CuNPs and Fe@Cu nanoparticles have a high affinity for all examined dyes with removal efficiency above $85 \%$. FeNPs were found to be very poor in removing staining dyes with highest removal efficiency of $58 \%$. The Fe@Cu nanoparticles were effective with over $90 \%$ removal efficiency for all tested dyes.

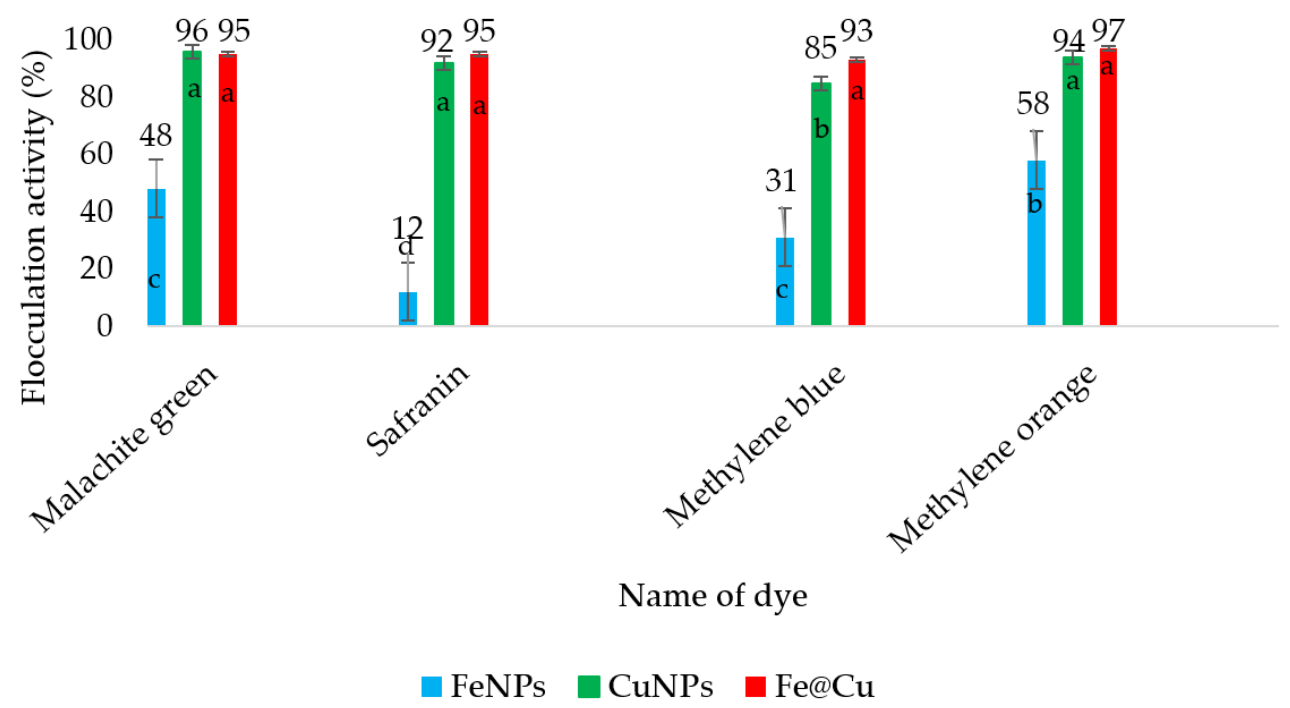

Figure 4. Application of nanoparticles on the removal of dyes at room temperature different letters $(\mathrm{a}, \mathrm{b}, \mathrm{c}$ and $\mathrm{d})$ are significantly different at $(p<0.05)$.

\subsection{Removal of Nutrients from Model Waters by Nanoparticles}

Table 2 below shows the removal of nutrients from model waters by nanoparticles. All the nanoparticles have an affinity for total nitrogen, but Fe@Cu nanoparticles were more effective to both phosphate and total nitrogen removal compared to iron and copper nanoparticles. Both the iron and copper nanoparticles were shown to have poor removal efficiency for total nitrogen, but Fe@Cu nanoparticles were more effective with $94 \%$ removal efficiency in Mzingazi water.

Table 2. Phosphate and total nitrogen removal in wastewater by nanoparticles under room temperature.

\begin{tabular}{cccccccc}
\hline \multirow{2}{*}{ Flocculants } & Wastewater Type & \multicolumn{2}{c}{$\begin{array}{c}\text { Water Quality before } \\
\text { Treatment (Control) }\end{array}$} & $\begin{array}{c}\text { Water Quality after } \\
\text { Treatment (Flocculants) }\end{array}$ & Removal Efficiency (\%) \\
\cline { 3 - 8 } & & Phosphate & $\begin{array}{c}\text { Total } \\
\text { Nitrogen }\end{array}$ & Phosphate & $\begin{array}{c}\text { Total } \\
\text { Nitrogen }\end{array}$ & Phosphate & $\begin{array}{c}\text { Total } \\
\text { Nitrogen }\end{array}$ \\
\cline { 3 - 8 } & Vulindlela & $3.38 \pm 0.0$ & $0.127 \pm 0.0$ & $1.62 \pm 0.1$ & $0.022 \pm 0.0$ & 52 & 83 \\
\multirow{2}{*}{ CuNPs } & Mzingazi & $85.7 \pm 0.0$ & $0.223 \pm 0.0$ & $7.521 \pm 0.1$ & $0.108 \pm 0.0$ & 92 & 52 \\
& Vulindlela & $3.38 \pm 0.0$ & $0.127 \pm 0.0$ & $1.64 \pm 0.0$ & $0.019 \pm 0.0$ & 51 & 85 \\
\multirow{2}{*}{ FeNPs } & Mzingazi & $85.7 \pm 0.0$ & $0.223 \pm 0.0$ & $9.102 \pm 0.0$ & $0.127 \pm 0.0$ & 90 & 45 \\
& Vulindlela & $3.38 \pm 0.0$ & $0.127 \pm 0.0$ & $0.09 \pm 0.0$ & $0.020 \pm 0.0$ & 97 & 84 \\
\multirow{2}{*}{$\mathrm{Fe@Cu}$} & Mzingazi & $85.7 \pm 0.0$ & $0.223 \pm 0.0$ & $0.109 \pm 0.0$ & $0.014 \pm 0.0$ & 99 & 94 \\
\hline
\end{tabular}

\subsection{COD and BOD Removal From Coal Mine Wastewater and Mzingazi River Water}

Table 3 below shows the removal efficiency for COD and BOD by nanoparticles (FeNPs, CuNPs and Fe@Cu) from coal mine wastewater and Mzingazi river water. The copper nanoparticles had the highest removal efficiency for both COD and BOD for all the water samples. 
Table 3. Removal efficiency for COD and BOD by nanoparticles (FeNPs, CuNPs and Fe@Cu) from coal mine wastewater and Mzingazi river water at room temperature.

\begin{tabular}{|c|c|c|c|c|c|}
\hline Flocculant & Types of Waste Water & $\begin{array}{c}\text { Types of } \\
\text { Pollutants in } \\
\text { Water }\end{array}$ & $\begin{array}{c}\text { Water Quality } \\
\text { before Treatment } \\
(\mathrm{mg} / \mathrm{L})\end{array}$ & $\begin{array}{l}\text { Water Quality } \\
\text { after Treatment } \\
(\mathrm{mg} / \mathrm{L})\end{array}$ & $\begin{array}{c}\text { Removal } \\
\text { Efficiency (\%) }\end{array}$ \\
\hline \multirow{4}{*}{ CuNPs } & Coal mine water & COD & $842 \pm 0.0$ & $103 \pm 0.0$ & 88 \\
\hline & \multirow{3}{*}{ Mzingazi river water } & BOD & $123.2 \pm 0.0$ & $4.12 \pm 0.0$ & 96 \\
\hline & & COD & $3.30 \pm 0.0$ & $0.28 \pm 0.0$ & 92 \\
\hline & & BOD & $136 \pm 0.0$ & $14 \pm 0.0$ & 89 \\
\hline \multirow{4}{*}{ FeNPs } & \multirow[t]{2}{*}{ Coal mine water } & COD & $842 \pm 0.0$ & $204 \pm 0.0$ & 76 \\
\hline & & BOD & $123.2 \pm 0.0$ & $23 \pm 0.0$ & 81 \\
\hline & \multirow[t]{2}{*}{ Mzingazi river water } & COD & $3.30 \pm 0.0$ & $1.70 \pm 0.0$ & 48 \\
\hline & & BOD & $136 \pm 0.0$ & $24 \pm 0.0$ & 82 \\
\hline \multirow{4}{*}{$\mathrm{Fe} @ \mathrm{Cu}$} & \multirow[t]{2}{*}{ Coal mine water } & COD & $842 \pm 0.0$ & $71 \pm 0.0$ & 92 \\
\hline & & BOD & $123.2 \pm 0.0$ & $3.41 \pm 0.0$ & 97 \\
\hline & \multirow[t]{2}{*}{ Mzingazi river water } & COD & $3.30 \pm 0.0$ & $0.79 \pm 0.0$ & 76 \\
\hline & & BOD & $136 \pm 0.0$ & $7.70 \pm 0.0$ & 94 \\
\hline
\end{tabular}

\subsection{Effect of the Type of Water on Flocculation Activity of Nanoparticles}

Different wastewater samples were examined including kaolin, coal mine wastewater and River water as indicated in Figure 5 below. The experiments were conducted at room temperature.

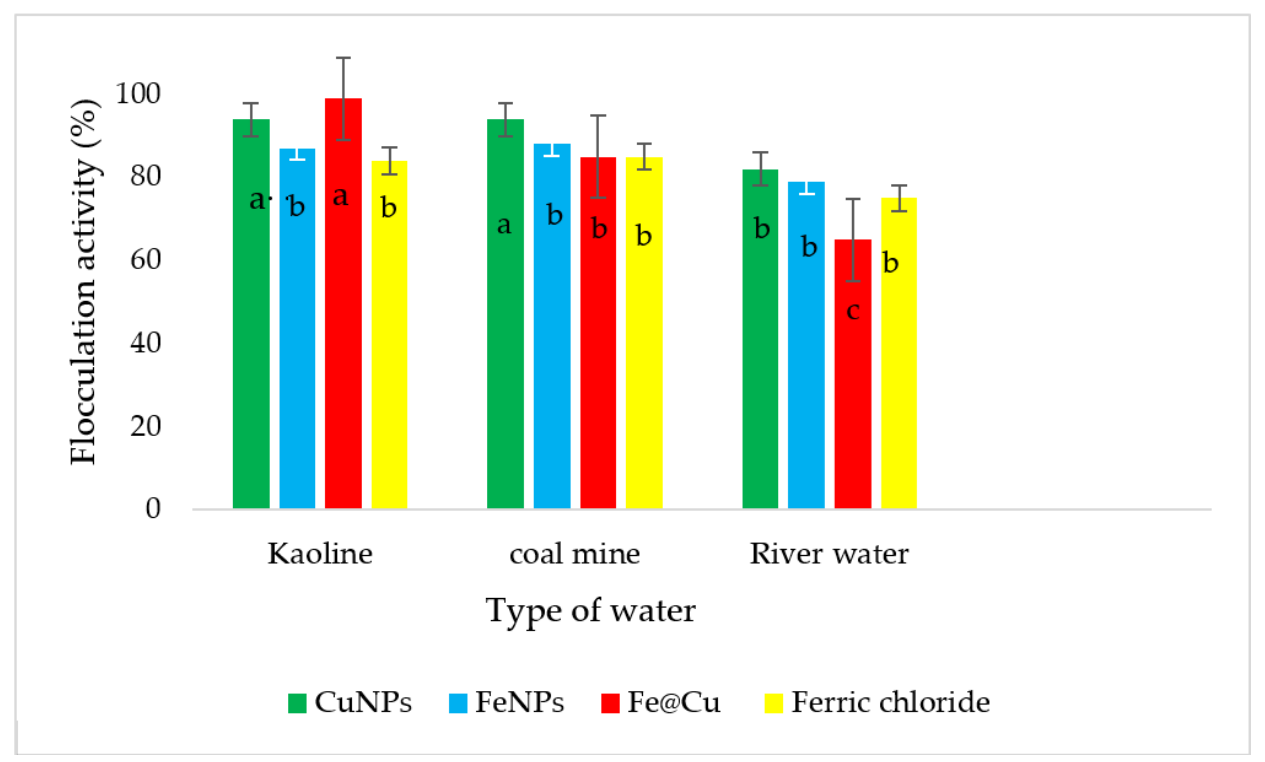

Figure 5. Flocculating efficiency of CuNPs, FeNPs and Fe@Cu nanoparticles and ferric chloride using kaolin clay, coal mine water and river water all data was collected in triplicates and the error bars in the Figures show the standard deviations of the data different letters $(\mathrm{a}, \mathrm{b}, \mathrm{c})$ are significantly $(p<$ 0.05) different.

\subsection{Antimicrobial Effect of Nanoparticles}

Table 4 shows the antimicrobial activity of nanoparticles (FeNPs, CuNPs and Fe@Cu) in comparison with Ciprofloxacin. Minimum Inhibitory Concentration (MIC) and Minimum Bactericidal Concentration (MBC) was observed for (CuNPs and Fe@Cu), while FeNPs nanoparticles did not have any antimicrobial effect on the tested strains. These studies were performed at an incubation temperature of $37^{\circ} \mathrm{C}$. 
Table 4. Antimicrobial activity of nanoparticles in comparison with ciprofloxacin.

\begin{tabular}{cccc}
\hline Bacterial Strain & Antimicrobial Agent & MIC $(\mathbf{m g} / \mathbf{m L})$ & MBC $(\mathbf{m g} / \mathbf{m L})$ \\
\hline \multirow{3}{*}{ E. coli } & FeNPs & - & - \\
& CuNPs & 3.125 & 3.125 \\
& Fe@Cu & 1.563 & 1.563 \\
& Ciprofloxacin & 12.5 & 12.5 \\
\hline \multirow{5}{*}{ B. subtilis } & FeNPs & - & - \\
& CuNPs & 3.125 & 3.125 \\
& Fe@Cu & 1.563 & 1.563 \\
& Ciprofloxacin & 6.25 & 6.25 \\
\hline
\end{tabular}

\subsection{In-Vitro Cytotoxicity of Nanoparticles}

Figures 6-8 illustrate the in-vitro cytotoxicity of nanoparticles (FeNPs, CuNPs and Fe@Cu) on HEK293 human embryonic cells and MCF7 breast cancer cells, respectively.

FeNPs

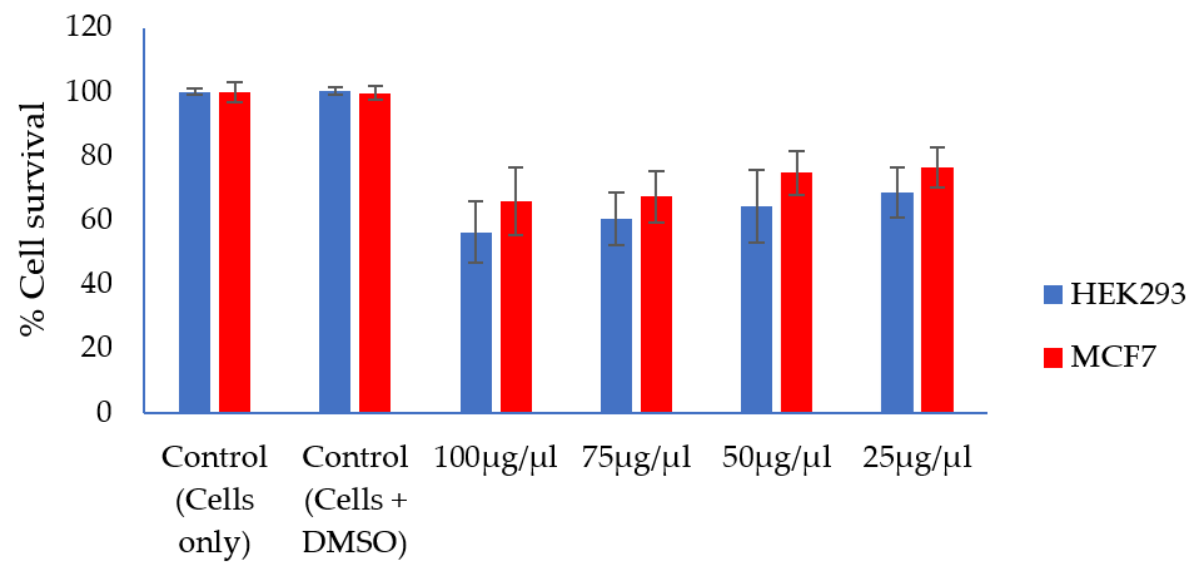

\section{Concentration}

Figure 6. In-vitro cytotoxicity effect of FeNPs nanoparticles on HEK293 and MCF7 cells.

\section{CuNPs}

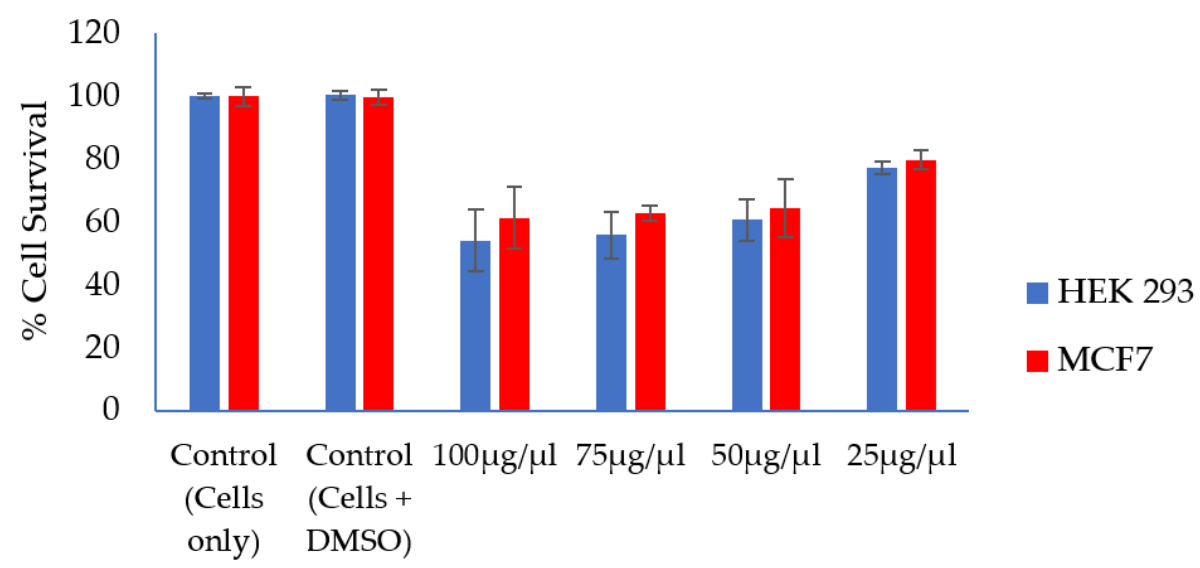

\section{Concentration}

Figure 7. In-vitro cytotoxicity effect of CuNPs nanoparticles on HEK293 and MCF7 cells. 


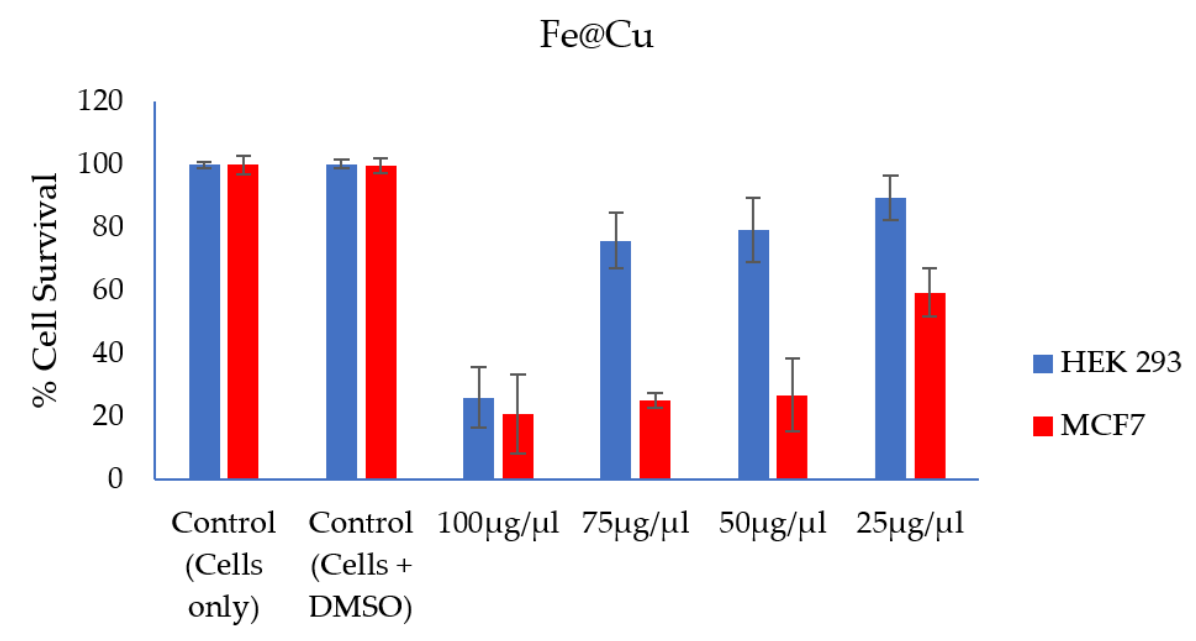

\section{Concentration}

Figure 8. In-vitro cytotoxicity effect of Fe@Cu nanoparticles on HEK293 and MCF7 cells.

\subsection{Biodegradation of Nanoparticles}

Table 5 represents biodegradation results for nanoparticles CuNPs, FeNPs and Fe@Cu. The Fe@Cu nanoparticles in week one were less degraded in comparison to both CuNPs and FeNPs. All experiments were conducted at room temperature.

Table 5. Biodegradation study on nanoparticles (CuNPs, FeNPs and Fe@Cu) at room temperature.

\begin{tabular}{ccccccc}
\hline \multirow{2}{*}{ Samples } & \multirow{2}{*}{ Initial Weight $(\mathbf{g})$} & \multicolumn{5}{c}{ Weight of Samples Remaining per Week (g) \pm SD } \\
\cline { 3 - 7 } & & $\mathbf{1}$ & $\mathbf{2}$ & $\mathbf{3}$ & $\mathbf{4}$ & $\mathbf{5}$ \\
\hline CuNPs & $0.17 \pm 0.00$ & $0.17 \pm 0.00$ & $0.17 \pm 0.00$ & $0.1 \pm 0.00$ & $0.03 \pm 0.00$ & $0.00 \pm 0.00$ \\
FeNPs & $0.21 \pm 0.00$ & $0.21 \pm 0.00$ & $0.19 \pm 0.00$ & $0.12 \pm 0.00$ & $0.01 \pm 0.00$ & $0.00 \pm 0.00$ \\
Fe@Cu & $0.23 \pm 0.00$ & $0.23 \pm 0.00$ & $0.06 \pm 0.00$ & $0.03 \pm 0.00$ & $0.02 \pm 0.01$ & $0.00 \pm 0.00$ \\
Control & $4.00 \pm 0.00$ & $4.00 \pm 0.00$ & $4.00 \pm 0.00$ & $4.00 \pm 0.00$ & $4.00 \pm 0.00$ & $4.00 \pm 0.00$ \\
(soil only) & & & & & & \\
\hline
\end{tabular}

\section{Discussion}

Single metallic FeNPs and CuNPs and bimetallic nanoparticles were successful synthesized using a green chemistry approach. Characterization of the as-synthesized material was achieved through the various analytical techniques such as UV-vis spectroscopy, Fourier transform-infrared spectroscopy (FT-IR), Thermogravimetric analysis (TGA), Scanning Electron Microscope (SEM), Transmission Electron Microscopy (TEM) and X-ray diffraction (XRD). UV-vis spectrum represents Surface plasmon resonance (SPR) spectra with absorbance at 280-390 nm and the peak maxima for the synthesized particles was observed at around $310 \mathrm{~nm}$ (Figure S1 (Supplementary Materials)). The absorption peaks at 200-340 nm were due to the presence of other biomolecules of microorganism extract responsible for the production of nanoparticles [16]. In the FeNPs and CuNPs, the absorption peak is observed at around a $295 \mathrm{~nm}$ wavelength. Therefore, we can assume from Figure S1 (Supplementary Materials) that the absorption band at $320 \mathrm{~nm}$ is due to the synthesized Fe@Cu nanoparticles. The shift to a higher wavelength may be due to the Fe and $\mathrm{Cu}$ mixture present in the Fe@Cu nanoparticles. The FT-IR analysis on the synthesized nanoparticles revealed the presence of hydroxyl group (-OH) and amine group (-NH$)$ in the sample (Figure S2 (Supplementary Materials)) through the band present at around $3244 \mathrm{~cm}^{-1}$. The aliphatic bonds present are designated by a weak band at $1646 \mathrm{~cm}^{-1}$ and an amide group is indicated by the peak present at $978 \mathrm{~cm}^{-1}$. The $-\mathrm{OH}$ group in alcohols is represented by the vibrational peaks at $523 \mathrm{~cm}^{-1}$, indicating the C-O stretching in alcohols [21]. Finally, according to UV-Vis and FT-IR spectrum FeNPs were significantly different from CuNPs and Fe@Cu as seen 
from Figure S2 (Supplementary Materials). Contrary to this, the FT-IR spectrum for Fe@Cu is different, the difference may be due to the way in which the polymer is bonded. TEM images (Figure S3 (Supplementary Materials)) revealed close to spherical shaped particles for the iron, copper and Fe@Cu nanoparticles. From the TEM images, it is clear that there is high degree of aggregation, which made it difficult to calculate the average particle sizes.

The SEM images disclose the morphology of the FeNP, CuNP and Fe@Cu nanoparticles (Figure S4). FeNPs displaying the distinct spherical particles (Figure S4a (Supplementary Materials)), CuNPs showing the large flaky particles (Figure S4b (Supplementary Materials)) and Fe@Cu nanoparticles exhibiting the stacking of the layers and larger particles (Figure S4c (Supplementary Materials)). SEM-EDX analysis highlighted the presence of various elements such as $\mathrm{O}, \mathrm{Fe}, \mathrm{P}, \mathrm{C}, \mathrm{Ca}, \mathrm{Cu}$ and $\mathrm{K}$ (Figures S5-S7 (Supplementary Materials)). From the SEM-EDX images, it can be observed that the Fe and $\mathrm{Cu}$ are more abundant in the FeNP, $\mathrm{CuNP}$ and Fe@Cu nanoparticles. The presence of $\mathrm{O}, \mathrm{P}, \mathrm{C}, \mathrm{S}, \mathrm{Cl}$, $\mathrm{Mg}$ and Ca elements represent the bioflocculant.

Powder X-ray diffraction analysis showed the peaks that are in crystalline nature of the synthesized material with no impurities (Figure S8a-c). The characteristic diffraction peaks of the CuNP and Fe@Cu nanoparticles are in correlation with the copper standard (JCPDS 04-0836). Figure S8a-c (Supplementary Materials)) illustrates the X-ray diffraction patterns of FeNPs, CuNPs and Fe@Cu nanoparticles synthesized from the bioflocculant. In FeNPs, broad peaks are seen between $2 \theta \sim 24^{\circ}$, $29^{\circ}, 30^{\circ}$ and $35^{\circ}$ for the as-synthesized iron nanoparticles. The peak broadening in the XRD patterns of the solids is generally attributed to particle size effects. Similarly, in CuNPs several intense peaks were observed at $20^{\circ}, 30^{\circ}, 33^{\circ}$ and $43^{\circ}$. In the as-synthesized CuNPs, in comparison to a copper standard (JCPDS 04-0836), the characteristic diffraction peaks of copper were observed at around $33^{\circ}$ and $47^{\circ} 2 \theta$. They correspond to the (111) and (220) planes of the fcc structure. From the Figure S8a-c (Supplementary Materials)), the diffraction peaks centered at $2 \theta \approx 13.2^{\circ}, 17.4^{\circ}, 21^{\circ}, 23^{\circ}, 25^{\circ}, 29.3^{\circ}, 34^{\circ}$, $38^{\circ}, 43$ and $44.8^{\circ}$ corresponding to the copper and iron [33,34]. The diffraction peak of iron at $44.8^{\circ}$ is hidden under the pattern of copper due to the overlap of their peaks [35]. As shown above, the data indicates both iron and copper. This again confirms the iron copper synthesis was a success.

TGA patterns reveal the three phases degradation pattern for iron nanoparticles (Figure S9a (Supplementary Materials)). Approximately, at 60 to $200^{\circ} \mathrm{C}$, the first phase is observed that could be the result of a loss in moisture content or drying of the residual solvent which was used during purification. At above 250 and below $550{ }^{\circ} \mathrm{C}$, the second phase is observed; this could be related to decomposition of polymer, which in turn resulted in weight loss. Further increase in temperature resulted in more weight loss in the synthesized nanoparticles. At temperatures above $800{ }^{\circ} \mathrm{C}$ the weight of the sample slightly above $50 \%$ suggesting that the material is thermostable. Similarly, three phases that can be noticed in the thermogravimetric analysis of cooper nanoparticles (Figure S9b (Supplementary Materials)). From temperatures 40 to $120^{\circ} \mathrm{C}$ the first phase can be noticed as the result of loss in moisture content or drying of residual solvent which was used during purification. The second phase is observed at temperatures around $150{ }^{\circ} \mathrm{C}$ and below $200{ }^{\circ} \mathrm{C}$, this could be related to decomposition of polymer which in turn resulted in weight loss. Moreover, further increase in temperature resulted in more weight loss in the synthesized nanoparticles. A similar trend is observed for Fe@Cu nanoparticles as in FeNPs. Where the first phase is observed between 150 and $200{ }^{\circ} \mathrm{C}$, with the increase in temperature up to $300^{\circ} \mathrm{C}$ the second phase of the Fe@Cu was observed (Figure S9c). Further weight loss resulted from increased temperature.

As shown in Figure 1, CuNPs and Fe@Cu nanoparticles had the highest flocculation activity of $99 \%$ and $96 \%$, respectively, at a low concentration of $0.2 \mathrm{mg} / \mathrm{mL}$, while the optimum flocculation activity for FeNPs was achieved at $0.4 \mathrm{mg} / \mathrm{mL}$ with $82 \%$ flocculation activity. With the increased dosage concentration of the nanoparticles, flocculation activity for both CuNPs and Fe@Cu started to decrease. This could be due to the increased viscosity as the result of excess dosage sizes that negatively affect the settling and stability of the flocs [20]. Contrary to this, the flocculation activity of FeNPs kept on fluctuating with the increase in dosage of nanoparticles concentration. This could be attributed to 
an inadequate flocculant concentration does not sufficiently neutralize some of the negative charges on colloidal particles and thus results in low activity. Fe@Cu nanoparticles worked efficiently at low concentration with $99 \%$ flocculation activity at $0.2 \mathrm{mg} / \mathrm{mL}$. Destabilized kaolin particles suspension results from excessive bioflocculant, which in turn results into repulsion of negatively charged kaolin particles. Flocculation activity decreases with the increase in dosage of concentration [26]. This could have resulted from kaolin binding site blockage by excess flocculating agent present. Contrary to these findings, the bridging phenomena could not be effectively formed when the dosage of the bioflocculant was too low [36].

Cations have stimulating effect on the adsorption of bioflocculant on the suspended kaolin particles by decreasing the negative charge of both the polymer and particles. Cations neutralize and stabilize the negative charge of the functional groups of colloidal kaolin particles in solution and the bioflocculant [37]. Iron nanoparticles are cation dependent with $85 \%$ flocculation activity when $\mathrm{Fe}^{3+}$ was used as opposed to $46 \%$ flocculation activity when there was no cation present. Contrary to this, the synthesized copper nanoparticles are more effective without the addition of a cation with 96\% flocculation activity. In comparison to both iron and copper nanoparticles, Fe@Cu nanoparticles proved to have best flocculation ability. All the cations (monovalent, divalent and trivalent) enhanced the flocculation of Fe@Cu nanoparticles. However, it was observed that the flocculation activity was above $95 \%$ in the absence of a cation.

One of the key factors which influences the flocculation process is $\mathrm{pH}$ of the reaction mixture [38]. Flocculation efficiency may be affected by $\mathrm{pH}$, which could have altered the flocculant charge status and surface characteristics of the colloidal particles [26]. Different flocculants have been reported to produce flocculating efficiency with optimal activity at varying $\mathrm{pH}$ values [39]. $\mathrm{NaOH}(0.1 \mathrm{M})$ and $\mathrm{HCl}$ $(0.1 \mathrm{M})$ solutions were used to adjust the $\mathrm{pH}$ of the kaolin solutions whenever it was necessary. It can be observed from Figure 2 that a strong flocculation activity at all pH ranges for Fe@Cu nanoparticles, from strong acidic to strong alkaline $\mathrm{pH}$, and the flocculation activity was above $95 \%$. These findings are in good agreement with the literature, which states that bimetallic nanoparticles can withstand harsh conditions, such as extreme $\mathrm{pH}$ and temperatures, and have improved properties as opposed to single metal nanoparticles [40]. The FeNPs flocculation activity remained constant at $77 \%$ both at acidic and neutral $\mathrm{pH}$ and there was significantly sharp increased from 77-95\% at an alkaline $\mathrm{pH}$ suggesting that FeNPs were more efficient in an alkaline $\mathrm{pH}$. To achieve high flocculation activity for CuNPs the adjustment of $\mathrm{pH}$ is not necessary, as the maximum flocculation activity of $96 \%$ was achieved at neutral $\mathrm{pH} 7$. However, the lowest flocculation activity of $55 \%$ was achieved at acidic $\mathrm{pH} 3$. This could have been due to the fact that the conditions at which the nanoparticles were synthesized using bioflocculant have varied electric charges with $\mathrm{pH}$ variation, influencing the nanoparticles' bridging effectiveness $[20,40]$. Consequently, it could be deduced that the spatial arrangements of charge at $\mathrm{pH} 3$ were not encompassing. Bacillus velezenis 404 bioflocculant was found to be stable at $\mathrm{pH}$ range 3-9 and the optimum flocculation ability was reached at $\mathrm{pH} 7$ [41]. Like many other flocculants reported in literature, the synthesized copper nanoparticles flocculate in a wide range of $\mathrm{pH}$ suggesting that it is a stable at different $\mathrm{pH}$ levels with an optimum flocculation activity at $\mathrm{pH} 7$.

Thermostability of the nanoparticles was evaluated by heating the nanoparticles in the water bath for $30 \mathrm{~min}$ at temperatures 60,80 and $100{ }^{\circ} \mathrm{C}$ from Figure 3 [42]. Both the CuNPs and Fe@Cu nanoparticles retained over $90 \%$ flocculation activity. Meanwhile, FeNPs retained over $88 \%$ flocculation suggesting that the nanoparticles were very thermostable. Subjected to various temperatures applied, the flocculation activity remained above 88\% with the Fe@Cu nanoparticles showing the highest flocculation activity. Therefore, it was deduced that the nanoparticles were thermo-stable, and its flocculation activity was not affected when the temperature was elevated. Bioflocculant sensitivity is associated with the presence of peptide or protein in the structure of the bioflocculant. Contrary to this, the bioflocculant, which consists of sugars on its structure, is mostly heat stable [43]. The bioflocculant, which was used for nanoparticles synthesis, is a polysaccharide and contains hydroxyl groups. The presence of the hydroxyl group could be responsible for the thermal stability of nanoparticles. 
Moreover, the Fe@Cu nanoparticles are resistant to harsh conditions and this is due to the synergistic effect between iron and copper [44].

The potential of nanoparticles (FeNPs, CuNPs and Fe@Cu) to remove dyes was investigated. Copper and Fe@Cu nanoparticles were able to remove all different dyes, while iron nanoparticles had an average of below $50 \%$ removal efficiency. All the experiments were carried out at room temperature. The optimum dosage concentration for each nanoparticle was found to be as $0.2 \mathrm{mg} / \mathrm{mL}$ for CuNPs and $0.4 \mathrm{mg} / \mathrm{mL}$ for FeNPs. It is clear from Figure 4 that both the CuNPs and Fe@Cu nanoparticles were able to remove all the dyes and Fe@Cu had the highest removal efficiency of above $90 \%$ for all the tested dyes. Iron nanoparticles had the poorest results with the removal efficiency below $50 \%$ for most of the dyes. Poor performance of the FeNPs could be attributed parameters such as low dosage of the nanoparticles, $\mathrm{pH}$ of the dye solution and insufficient contact time between dye solution and FeNPs nanoparticles. Contrary to this, in a study by Shahwan, et al. [45] iron nanoparticles removed both the methylene blue and methylene orange completely. However, the concentration $50 \mathrm{mg} / \mathrm{L}$ could only manage to remove both methylene blue and methyl orange after $6 \mathrm{hrs}$.

Phosphorus is an essential element for the growth of plants and animals. However, it is very toxic in its elemental form as it can result in the formation of $\mathrm{PO}_{4}{ }^{3-}$ and is subjected to accumulation [46]. There are three forms of phosphate that exist: met-pho sulphate, orthophosphate and organically bound phosphate. A different chemical formula is contained in each compound, ortho forms are produced naturally and are found in sewage. Ortho forms are important in nature and result from poly phosphate forms, which are used for treating boiler water and in detergents. Breakdown of organic pesticides, which contain phosphate, results into the occurrence of ortho forms. Table 2 shows that Fe@Cu nanoparticles were able to remove up to $97 \%$ phosphate in wastewater in comparison to copper and iron nanoparticles. The fertilizers used by farmers contains phosphate and various amounts phosphate is washed into waterbodies. Phosphate presence in water improves the overall water quality by stimulating the growth of aquatic plants and plankton, which provide food for fish, and increases the population growth of fish. However, excess phosphate may cause over-fertilization of receiving waters and eutrophication by stimulating the growth of algal and aquatic plants. Consequently, vegetation and quality life may decay due to decreased dissolved oxygen levels. Extreme levels of phosphate can be toxic to people and animals [46]. From Table 2 above the removal of phosphate in Mzingazi river was evaluated. Initially, all the nanoparticles had a removal efficiency below $40 \%$. However, drastic increase in phosphate removal was observed (up to $90 \%$ ) when wastewater treated with nanoparticles was left standing for a week, as depicted in Table 2. Signifying that the contact time is an important factor in the efficiency of nanoparticles. Phosphorus and nitrogen are the primary nutrients implicated on eutrophication, as eutrophication continues to be the primary concern to water quality [47]. Atmospheric deposit, fertilizers and vegetation are primary sources of nutrients in urban areas. Nutrients load can also be significantly added through maintenance, construction and soil management through the addition of fertilizers in the process of reviving injured vegetation [47]. Furthermore, nitrate and nitrite ions, which are part of nitrogen cycle, may result in increase of nitrogen. Nitrites in warm-blooded animals directly react with hemoglobin to produce methemoglobin, while in fish it results to a condition known as "brown blood disease". Methemoglobin destroys the ability of red blood cells to transport hemoglobin [46]. As shown in Table 2, Fe@Cu nanoparticles could remove up to $94 \%$ of total nitrogen in comparison to both iron and copper nanoparticles with 45 and 52\%, respectively. Therefore, it can be deduced that Fe@Cu nanoparticles are more effective to remove phosphate and total nitrogen from the Vulindlela treatment plant and Mzingazi river water. The binding affinity of the metal nanoparticles to the dyes containing azo groups, $\mathrm{P}$ and $\mathrm{N}$ is high. This could be the possible mechanism for the removal of dyes, $\mathrm{P}$ and $\mathrm{N}$ from the wastewater.

Both the high amount of COD and BOD in water will result in a decrease of dissolved oxygen (DO). Reduced oxygen dissolving leads to anaerobic conditions, which are detrimental to higher aquatic life forms. Higher amounts of BOD in water indicates a high amount of nutrients in water. This condition is not healthy for the environment, as it also may result in an alga boom. Tendele coal 
mine wastewater, KwaZulu Natal, South Africa and Mzingazi river water were selected for the application of nanoparticles (FeNPs, CuNPs and Fe@Cu) for the removal of COD and BOD. The COD and BOD for both water samples was measured before and after the application of nanoparticles. The COD for all the water samples was evaluated using the COD Cell Test, photometric method $25-1500 \mathrm{mg} / \mathrm{L}$ Spectroquant ${ }^{\circledR}$. Where $10 \mathrm{~mL}$ of the both untreated and treated wastewater samples were added in different COD cells and the cells were taken into a digester for $120 \mathrm{~min}$ at $150{ }^{\circ} \mathrm{C}$ after which the samples were taken for absorption analysis using a UV-Vis spectrophotometer at $620 \mathrm{~nm}$ wavelength. The concentration that was used for all the nanoparticles was $0.2 \mathrm{mg} / \mathrm{mL}$ and both the CuNPs and Fe@Cu nanoparticles exhibited good properties in all water samples for both the COD and BOD, with the Fe@Cu having the highest removal efficacy. Contrarily, FeNPs were very poor in removal of COD with $(<50 \%)$ in Mzingazi river and relatively good in coal mine COD removal with $76 \%$. However, for BOD, all three samples of nanoparticle (FeNPs, CuNPs and Fe@Cu) were able to remove above $80 \%$. Opposing this, in the study on the effectiveness of bioflocculant on COD removal in industrial wastewater, it was revealed that bioflocculant could only remove up to $60 \%$ of COD [48].

Several technologies have been reported in wastewater treatment, methods such as physical, chemical and biological, etc. There are numerous sources of water contamination, and these include industries and household. Industrial wastewater remains the largest contributor of the contamination [49]. The current study, Figure 5 was aimed at comparing the flocculating efficiency of the synthesized nanoparticles CuNPs, FeNPs and Fe@Cu with a commercial flocculant (ferric chloride). All the synthesized nanoparticles showed some remarkable ability to flocculate suspended particles in all the established water samples; however, CuNPs remained outstanding with a flocculation activity above $82 \%$ in all the samples. These findings suggest that nanoparticles, particularly copper nanoparticles can be used to flocculate coal mine and river water. This could be an alternative to harmful and non-degradable chemical flocculants [50]. All data were collected in triplicate and the error bars in the Figures show the standard deviations of the data.

Test bacterial strains for antimicrobial activity include a Gram-negative bacterium E. coli ATCC 25922 and a Gram-positive bacterium Bacillus subtilis CSM5. Both the (CuNPs and Fe@Cu) nanoparticles showed some remarkable properties for MIC and MBC against all the strains. Iron nanoparticles did not show any antimicrobial effect. The MIC and MBC for the Fe@Cu nanoparticles was achieved at the lowest concentration of $1.563 \mathrm{mg} / \mathrm{mL}$ for both strains. Similarly, the copper nanoparticles revealed some notable properties against the examined organisms. B. subtilis cell surface has carboxyl and amines group in abundant and copper is known to have greater affinity towards these groups which could be attributed to the sensitivity of $B$. subtilis against copper nanoparticles [51]. To evaluate the MBC, $p$-iodonitrotetrazolium (INT) indicator was used and all the wells which did not turn to red i.e., the wells, which had indicated a sensitivity towards the test strains, were further inoculated into a Muller Hilton agar and no growth was observed, which indicated that both the copper and Fe@Cu nanoparticles have a bactericidal effect.

A flocculant that is safe and efficient is required for wastewater treatment. In this study, in-vitro cytotoxicity of nanoparticles (FeNPs, CuNPs, and Fe@Cu) was investigated using an MTT reduction assay on HEK 293 and MCF7 cell lines. A compound used for the detection of viable cells that is based on the active metabolism of cells that are capable of converting MTT into a purple formazan is known as tetrazolium. From Figures $6-8$, all the nanoparticles at $25 \mu \mathrm{g} / \mu \mathrm{L}$ had cell viability over $70 \%$ for HEK 293 and Fe@Cu had the highest cell viability of $89 \%$. With increased concentration up to $75 \mu \mathrm{g} / \mu \mathrm{L}$ the Fe@Cu maintained 75\% cell viability for normal cells that indicates that Fe@Cu nanoparticles may not be toxic to HEK293 human embryonic cells. The FeNPs revealed that $66 \%$ of cells of MCF-7 were still viable at the highest concentration of $100 \mu \mathrm{g} / \mu \mathrm{L}$ and $56 \%$ of HEK 293 cells were viable at the highest concentration of $100 \mu \mathrm{g} / \mu \mathrm{L}$, which could, therefore, deduce that the FeNPs are considered safe. Contrary to that, CuNPs at $100 \mu \mathrm{g} / \mu \mathrm{L}$ showed $61 \%$ cell activity for MCF7 and $54 \%$ cell viability at the same highest concentration of $100 \mu \mathrm{g} / \mu \mathrm{L}$, which indicates that the CuNPs are safe to use at lower concentration. 
Vlasova, et al. [52] alluded that enzymes such as lysosomal hydrolases, peroxidase, isoforms of CYP450 etc. may be contributing to the biodegradation of nanoparticles. A role of variety microbial biodegradation enzymatic mechanisms has been reported and their roles in environmental nanoparticles biodegradation have been described [53]. Biodegradation study results for the nanoparticles (FeNPs, CuNPs and Fe@Cu) are presented in Table 5. All the bioflocculant-passivated nanoparticles were able to biodegrade completely after 5 weeks; however, the Fe@Cu nanoparticles drastically decreased in mass after two weeks. The initial mass of Fe@Cu nanoparticles decreased from $0.23 \mathrm{~g}$ to $0.06 \mathrm{~g}$, which is over $70 \%$ degradation. In the first two weeks, CuNPs could not degrade, the mass remained at the initial mass of $1.7 \mathrm{~g}$. Similarly, the FeNPs mass decreased from $0.23 \mathrm{~g}$ to $0.19 \mathrm{~g}$, which is just $17 \%$ degradation. This could be due to the structure modification of both FeNPs and CuNPs, thus making it difficult for enzymes to degrade in a short space of time [54].

\section{Conclusions}

Both CuNPs and Fe@Cu nanoparticles had the highest flocculation activity of 96\% and 99\%, respectively, at a low concentration of $0.2 \mathrm{mg} / \mathrm{mL}$, while the optimum flocculation activity for FeNPs was achieved at $0.4 \mathrm{mg} / \mathrm{mL}$ with $82 \%$ flocculation activity. Iron nanoparticles are cation dependent with $85 \%$ flocculation activity when $\mathrm{Fe}^{3+}$ was used as opposed to $46 \%$ flocculation activity when there was no cation present. Contrary to this, CuNPs and Fe@Cu nanoparticles flocculate well without the addition of cations and are pH stable. Both CuNPs and Fe@Cu nanoparticles have the remarkable ability to remove dyes. The synthesized nanoparticles work well in removing both the COD and BOD in river water and coal mine wastewater. When evaluated for antimicrobial activity, both CuNPs and Fe@Cu were able to inhibit and kill the Gram-positive and Gram-negative microorganisms, while FeNPs did not show any antimicrobial activity. In the cytotoxicity study, FeNPs and CuNPs nanoparticles were shown to be safer to use at a low concentration $25 \mu \mathrm{g} / \mu \mathrm{L}$, as the cell viability was above $68 \%$ again in HEK 293 and MCF7. Meanwhile, Fe@Cu has cell viability above 89\% for HEK 293 and 59\% viability against MCF7. After 7 weeks, all the nanoparticles were biodegraded by microorganisms. Further work will focus on more characterization of the synthesized materials to establish the physical mechanism responsible for formation and to verify if the material is complete/incompletely coated or in composite form or in structure. In addition, chemical characterization of the as-synthesized materials is essential to ascertain if iron and copper do not dissolve and disappear in water at $\mathrm{pH} 7$ and 11 and a mechanism of action in pollutants removal must be investigated.

Supplementary Materials: The supplementary materials are available online at http://www.mdpi.com/2227-9717/ 8/9/1125/s1.

Author Contributions: Conceptualization, A.K.B. and V.S.R.P.; formal analysis, N.G.D. and V.S.R.P.; investigation, N.G.D.; supervision, A.K.B. and V.S.R.P.; writing-original draft, N.G.D.; writing-review and editing, V.S.R.P. All authors have read and agreed to the published version of the manuscript.

Funding: Rajasekhar Pullabhotla would like to acknowledge the National Research Foundation (NRF, South Arica) for the financial support in the form of the Incentive Fund Grant (Grant No: 103691) and Research Developmental Grant for Rated Researchers (112145).

Acknowledgments: Nkosinathi Dlamini would like to acknowledge the Council for Scientific and Industrial Research (CSIR, South Africa) for the financial assistance in the form of the Ph.D. bursary. The authors would like to acknowledge the Electron Microscopy Unit at the University of KwaZulu-Natal, Westville campus, for providing support by letting us use the TEM and SEM-EDX facilities for the characterization of nanomaterials. The authors would like to acknowledge Moganavelli Singh, University of KwaZulu-Natal, Westville campus and her team for assisting with cytotoxicity tests. The authors would like to thank Tendele coal mine for supplying us with wastewater samples. Rajasekhar Pullabhotla would like to acknowledge the National Research Foundation (NRF, South Arica) for the financial support in the form of the Incentive Fund Grant (Grant No: 103691) and Research Developmental Grant for Rated Researchers (112145).

Conflicts of Interest: The authors declare that there is no conflict of interest. 


\section{References}

1. Li, O.; Lu, C.; Liu, A.; Zhu, L.; Wang, P.M.; Qian, C.D.; Jiang, X.H.; Wu, X.C. Optimization and characterization of polysaccharide-based bioflocculant produced by Paenibacillus elgii B69 and its application in wastewater treatment. Bioresour. Technol. 2013, 134, 87-93. [CrossRef] [PubMed]

2. Abdel-Halim, E.; Al-Deyab, S.S. Removal of heavy metals from their aqueous solutions through adsorption onto natural polymers. Carbohydr. Polym. 2011, 84, 454-458. [CrossRef]

3. Crini, G. Recent developments in polysaccharide-based materials used as adsorbents in wastewater treatment. Prog. Polym. Sci. 2005, 30, 38-70. [CrossRef]

4. Shih, I.; Van, Y.T.; Yeh, L.C.; Lin, H.G.; Chang, Y.N. Production of a biopolymer flocculant from Bacillus licheniformis and its flocculation properties. Bioresour. Technol. 2001, 78, 267-272. [CrossRef]

5. Moussavi, G.; Mahmoudi, M. Removal of azo and anthraquinone reactive dyes from industrial wastewaters using MgO nanoparticles. J. Hazard. Mater. 2009, 168, 806-812. [CrossRef] [PubMed]

6. Sondi, I.; Salopek-Sondi, B. Silver nanoparticles as antimicrobial agent: A case study on E. coli as a model for Gram-negative bacteria. J. Colloid Interface Sci. 2004, 275, 177-182. [CrossRef]

7. Dlamini, N.G.; Basson, A.K.; Pullabhotla, R.V. Optimization and application of bioflocculant passivated copper nanoparticles in the wastewater treatment. Int. J. Environ. Res. Public Health 2019, 16, 2185. [CrossRef]

8. Qu, X.; Alvarez, P.; Li, Q. Applications of nanotechnology in water and wastewater treatment. Water Res. 2013, 47, 3931-3946. [CrossRef]

9. Kolár̆, M.; Urbánek, K.; Látal, T. Antibiotic selective pressure and development of bacterial resistance. Int. J. Antimicrob. Agents 2001, 17, 357-363. [CrossRef]

10. Dlamini, N.G.; Basson, A.K.; Simonis, J.; Pullabhotla, R.V. Biosynthesis of bioflocculant passivated copper nanoparticles, characterization and application. Phys. Chem. Earth Parts A/B/C 2020, 102898. [CrossRef]

11. Dlamini, N.G.; Basson, A.K.; Pullabhotla, R.V. Wastewater treatment by a polymeric bioflocculant and iron nanoparticles synthesized from a bioflocculant. Polymers 2020, 12, 1618. [CrossRef] [PubMed]

12. Huang, D.; Chen, G.M.; Zeng, G.M.; Xu, P.; Yan, M.; Lai, C.; Zhang, C.; Li, N.J.; Cheng, M.; He, X.X.; et al. Synthesis and application of modified zero-valent iron nanoparticles for removal of hexavalent chromium from wastewater. Water Air Soil Pollut. 2015, 226, 375. [CrossRef]

13. Xu, P.; Zeng, G.; Huang, D.; Feng, C.L.; Hu, S.; Zhao, M.H.; Lai, C.; Wei, Z.; Huang, C.; Xie, G.X.; et al. Use of iron oxide nanomaterials in wastewater treatment: A review. Sci. Total. Environ. 2012, 424, 1-10. [CrossRef] [PubMed]

14. Devatha, C.; Thalla, A.K.; Katte, S.Y. Green synthesis of iron nanoparticles using different leaf extracts for treatment of domestic waste water. J. Clean. Prod. 2016, 139, 1425-1435. [CrossRef]

15. Khatami, M.; Alijani, H.Q.; Nejad, M.S.; Varma, R.S. Core@shell nanoparticles: Greener synthesis using natural plant products. Appl. Sci. 2018, 8, 411. [CrossRef]

16. Kaur, P.; Thakur, R.; Malwal, H.; Manuja, A.; Chaudhury, A. Biosynthesis of biocompatible and recyclable silver/iron and gold/iron core-shell nanoparticles for water purification technology. Biocatal. Agric. Biotechnol. 2018, 14, 189-197. [CrossRef]

17. Bhaumik, A.; Haque, A.; Karnati, P.; Taufique, M.F.N.; Patel, R.; Ghosh, K. Copper oxide based nanostructures for improved solar cell efficiency. Thin Solid Films 2014, 572, 126-133. [CrossRef]

18. Vasireddi, R.; Paul, R.; Mitra, A.K. Green synthesis of agcorecushell nanoparticles: Structural and optical characterization. J. Green Sci. Technol. 2013, 1, 85-90. [CrossRef]

19. Korbekandi, H.; Jouneghani, R.M.; Mohseni, S.; Pourhossein, M.; Iravani, S. Synthesis of silver nanoparticles using biotransformations by Saccharomyces boulardii. Green Process. Synth. 2014, 3, 385-406. [CrossRef]

20. Tsolanku, S.M.; Basson, A.K.; Dlamini, N.G. Removal of pollutants in mine wastewater by a non-cytotoxic polymeric bioflocculant from alcaligenes faecalis HCB2. Int. J. Environ. Res. Public Health 2019, 16, 4001. [CrossRef]

21. Dlamini, N.G.; Basson, A.K.; Pullabhotla, V.S.R.R. Biosynthesis and characterization of copper nanoparticles using a bioflocculant extracted from alcaligenis faecalis HCB2. Adv. Sci. Eng. Med. 2019, 11, 1064-1070. [CrossRef]

22. Nkosinathi, D.G.; Albertus, B.K.; Jabulani, S.S.E.; Siphephelo, M.S.; Pullabhotla, R.V. Biosynthesis, characterization, and application of iron nanoparticles: In dye removal and as antimicrobial agent. Water Air Soil Pollut. 2020, 231, 1-10. [CrossRef] 
23. Yu, X.; Li, J.; Shi, T.; Cheng, C.; Liao, G.; Fan, J.; Li, T.; Tanga, Z. A green approach of synthesizing of Cu-Ag core-shell nanoparticles and their sintering behavior for printed electronics. J. Alloys Compd. 2017, 724, 365-372. [CrossRef]

24. Dlamini, N.G.; Basson, A.K.; Emmanuel, S.J.S.; Pullabhotla, R.V. Optimization of Fe@Cu core-Shell nanoparticle synthesis, characterization, and application in dye removal and wastewater treatment. Catalysts 2020, 10, 755. [CrossRef]

25. Nomoev, A.; Bardakhanov, S.; Schreiber, M.; Bazarova, D.G.; Romanov, N.A.; Baldanov, B.B.; Radnaev, B.R.; Syzrantsev, V.V. Structure and mechanism of the formation of core-Shell nanoparticles obtained through a one-step gas-phase synthesis by electron beam evaporation. Beilstein J. Nanotechnol. 2015, 6, 874-880. [CrossRef] [PubMed]

26. Xia, X.; Lan, S.; Li, X.; Xie, Y.; Liang, Y.; Yan, P.; Chen, Z.; Xing, Y. Characterization and coagulation-flocculation performance of a composite flocculant in high-turbidity drinking water treatment. Chemosphere 2018, 206, 701-708. [CrossRef]

27. Agunbiade, M.; Pohl, C.; Ashafa, A.O.T. Bioflocculant production from Streptomyces platensis and its potential for river and waste water treatment. Braz. J. Microbiol. 2018, 49, 731-741. [CrossRef]

28. Daniels, A.N.; Singh, M. Sterically stabilized siRNA:gold nanocomplexes enhance c-MYC silencing in a breast cancer cell model. Nanomedicine 2019, 14, 1387-1401. [CrossRef]

29. Maliehe, T.S.; Shandu, J.S.; Basson, A.K.; Sidney, M.T.; Siyabonga, S.J.; Kotze, B.A. The antibacterial and antidiarreal activities of the crude methanolic Syzygium cordatum [S.Ncik, 48 (UZ)] fruit pulp and seed extracts. J. Med. Plants Res. 2015, 9, 884-891. [CrossRef]

30. Eloff, J.N. A Sensitive and quick microplate method to determine the minimal inhibitory concentration of plant extracts for bacteria. Planta Med. 1998, 64, 711-713. [CrossRef]

31. Mittal, H.; Mishra, S.B.; Mishra, A.K.; Kaith, B.; Jindal, R.; Kalia, S. Preparation of poly (acrylamide-co-acrylic acid)-grafted gum and its flocculation and biodegradation studies. Carbohydr. Polym. 2013, 98, 397-404. [CrossRef] [PubMed]

32. Kale, G.; Auras, R.; Singh, S.P.; Narayan, R. Biodegradability of polylactide bottles in real and simulated composting conditions. Polym. Test. 2007, 26, 1049-1061. [CrossRef]

33. Lu, Z.H.; Li, J.; Zhu, A.; Yao, Q.; Huang, W.; Zhou, R.; Zhou, R.; Chen, X. Catalytic hydrolysis of ammonia borane via magnetically recyclable copper iron nanoparticles for chemical hydrogen storage. Int. J. Hydrogen Energy 2013, 38, 5330-5337. [CrossRef]

34. Bish, D.L.; Post, J.E. Modern Powder Diffraction; Walter de Gruyter GmbH \& Co KG: Berlin, Germany, 2018; Volume 20.

35. Ban, Z.; Barnakov, Y.A.; Li, F.; Golub, V.; O'Connor, C.J. The synthesis of core-shell iron@gold nanoparticles and their characterization. J. Mater. Chem. 2005, 15, 4660-4662. [CrossRef]

36. Gong, W.X.; Wang, S.G.; Sun, X.F.; Liu, X.W.; Yue, Q.Y.; Gao, B. Bioflocculant production by culture of Serratia ficaria and its application in wastewater treatment. Bioresour. Technol. 2008, 99, 4668-4674. [CrossRef]

37. El-Salam, A.E.A.; Abd-El-Haleem, D.; Youssef, A.S.; Zaki, S.; Abu-Elreesh, G.; El-Assar, S.A. Isolation, characterization, optimization, immobilization and batch fermentation of bioflocculant produced by Bacillus aryabhattai strain PSK1. J. Genet. Eng. Biotechnol. 2017, 15, 335-344. [CrossRef]

38. Zaki, A.; Elkady, M.F.; Farag, S.; Abd-El-Haleem, D. Characterization and flocculation properties of a carbohydrate bioflocculant from a newly isolated Bacillus velezensis 40B. J. Environ. Biol. 2013, 34, 51.

39. Devi, K.K.; Natarajan, K. Production and characterization of bioflocculants for mineral processing applications. Int. J. Miner. Process. 2015, 137, 15-25. [CrossRef]

40. Zhu, C.; Chen, C.; Zhao, L.; Zhang, Y.; Yang, J.; Song, L.; Yang, S. Bioflocculant produced by Chlamydomonas reinhardtii. Environ. Biol. Fishes 2011, 24, 1245-1251. [CrossRef]

41. Xia, S.; Zhang, Z.; Wang, X.; Yang, A.; Chen, L.; Zhao, J.; Leonard, D.; Jaffrezic-Renault, N. Production and characterization of a bioflocculant by Proteus mirabilis TJ-1. Bioresour. Technol. 2008, 99, 6520-6527. [CrossRef]

42. Sun, J.; Zhang, X.; Miao, X.; Zhou, J. Preparation and characteristics of bioflocculants from excess biological sludge. Bioresour. Technol. 2012, 126, 362-366. [CrossRef] [PubMed]

43. Salehizadeh, H.; Shojaosadati, S. Extracellular biopolymeric flocculants. Recent trends and biotechnological importance. Biotechnol. Adv. 2001, 19, 371-385. [CrossRef]

44. Lin, Z.Z.; Huang, C.; Huang, Z.; Zhen, W.K. Surface/interface influence on specific heat capacity of solid, shell and core-shell nanoparticles. Appl. Therm. Eng. 2017, 127, 884-888. [CrossRef] 
45. Shahwan, T.; Abu Sirriah, S.; Nairat, M.; Boyacı, E.; Eroglu, A.E.; Scott, T.; Hallam, K. Green synthesis of iron nanoparticles and their application as a Fenton-like catalyst for the degradation of aqueous cationic and anionic dyes. Chem. Eng. J. 2011, 172, 258-266. [CrossRef]

46. Puri, A.; Kumar, M. A review of permissible limits of drinking water. Indian J. Occup. Environ. Med. 2012, 16, 40-44. [CrossRef] [PubMed]

47. Davis, A.P.; Shokouhian, M.; Sharma, H.; Minami, C. Water quality improvement through bioretention media: Nitrogen and phosphorus removal. Water Environ. Res. 2006, 78, 284-293. [CrossRef] [PubMed]

48. Patil, S.V.; Patil, C.D.; Salunke, B.K.; Salunkhe, R.B.; Bathe, G.A.; Patil, D.M. Studies on characterization of bioflocculant exopolysaccharide of azotobacter indicus and its potential for wastewater treatment. Appl. Biochem. Biotechnol. 2010, 163, 463-472. [CrossRef]

49. Lu, H.; Wang, J.; Wang, T.; Wang, N.; Bao, Y.; Hao, H. Crystallization techniques in wastewater treatment: An overview of applications. Chemosphere 2017, 173, 474-484. [CrossRef]

50. Exley, C.; Korchazhkina, O.; Job, D.; Strekopytov, S.; Polwart, A.; Crome, P. Non-invasive therapy to reduce the body burden of aluminium in Alzheimer's disease. J. Alzheimers Dis. 2006, 10, 17-24. [CrossRef]

51. Ruparelia, J.P.; Chatterjee, A.K.; Duttagupta, S.P.; Mukherji, S. Strain specificity in antimicrobial activity of silver and copper nanoparticles. Acta Biomater. 2008, 4, 707-716. [CrossRef]

52. Vlasova, I.I.; Kapralov, A.A.; Michael, Z.P.; Burkert, S.C.; Shurin, M.R.; Star, A.; Shvedova, A.A.; Kagan, V.E. Enzymatic oxidative biodegradation of nanoparticles: Mechanisms, significance and applications. Toxicol. Appl. Pharmacol. 2016, 299, 58-69. [CrossRef] [PubMed]

53. Zhang, L.; Petersen, E.J.; Habteselassie, M.Y.; Mao, L.; Huang, Q. Degradation of multiwall carbon nanotubes by bacteria. Environ. Pollut. 2013, 181, 335-339. [CrossRef] [PubMed]

54. Singh, R.P.; Karmakar, G.P.; Rath, S.K.; Karmakar, N.C.; Pandey, S.R.; Tripathy, T.; Panda, J.; Kanan, K.; Jain, S.K.; Lan, N.T. Biodegradable drag reducing agents and flocculants based on polysaccharides: Materials and applications. Polym. Eng. Sci. 2000, 40, 46-60. [CrossRef]

(C) 2020 by the authors. Licensee MDPI, Basel, Switzerland. This article is an open access article distributed under the terms and conditions of the Creative Commons Attribution (CC BY) license (http://creativecommons.org/licenses/by/4.0/). 